\title{
Empirical Characterization of Mass Evacuation Traffic Flow
}

\author{
Brian Wolshon, Ph.D., P.E. \\ Associate Professor \\ Department of Civil and Environmental Engineering \\ Louisiana State University, Baton Rouge, LA 70803-6405 \\ Ph: (225) 578-5247, Fax: (225) 578-5263, email: brian@rsip.lsu.edu
}

Resubmission Date: November 9, 2007

Word Count: 7,679 word equiv.=6,429 words + 6 Tables and Figures @ 250 word equiv./ea.

\begin{abstract}
Among the many gaps in the current state of mass evacuation planning and analysis practice, has been a lack of field-based study of traffic flow under actual evacuation conditions. Without observational studies of such conditions, simulations and forecasts of roadway performance during emergencies has historically been based conjecture and professional judgment. However, the recent series of hurricane evacuations along the Gulf Coast have given an opportunity to collect and evaluate traffic conditions during evacuation scenarios. This paper uses recently collected traffic data from two recent evacuations in Louisiana to assess how well various roadway classifications in different geographic areas are able to carry traffic during emergencies under both normal- and contra-flow operation. The objectives were to characterize the general conditions of traffic flow under an evacuation condition and to address lingering questions related to maximum sustainable flows and examine how they compared to those suggested by the Highway Capacity Manual (HCM). The findings of this work suggest that during evacuations, most roadways carry flows well below HCM predicted maximums and that despite the enormous demand conditions generated by a mass evacuation, maximum flows on urban roadways typically do not even reach those of typical daily commuter periods.
\end{abstract}

\section{KEYWORDS}

Evacuation, traffic flow measurement, capacity, contraflow, reversible lanes, reversible traffic flow, convertible lanes 
In August 2005, Hurricane Katrina made landfall on the Gulf Coast of Louisiana and Mississippi bringing wind and flood damage on an unprecedented scale. Fortunately, however, Hurricane Katrina also came after the development of innovative and proactive traffic management techniques that were conceived to increase the effectiveness of mass evacuations. Although glaring weaknesses existed in Louisiana's ability to evacuate many of the most vulnerable populations, like the elderly, infirm, and economically disadvantaged; the movement of people with the means and desire to evacuate in the hours before Katrina was accomplished at levels that exceeded the most optimistic prior projections. Studies by federal and state officials in the years before Katrina estimated about 72 hours would be required to fully evacuate the New Orleans metropolitan area (1). Traffic data collected during the Katrina evacuation suggest that it was actually completed in nearly half of this time.

The relative success of the Katrina evacuation in Louisiana has been attributed to several factors, including the good fortune that the majority of the traffic movement took place over a weekend when traffic was generally lighter, no major traffic restricting incidents occurred, and the storm characteristics were such that adverse weather conditions did not significantly impede the ability to travel until shortly before the storm's arrival. However, the primary factor cited for the effectiveness of the process was the region-wide evacuation traffic management plan that was developed by state department of transportation (DOT) and state police agencies.

The key features of the plan were the channelization of traffic onto routes and into directions that increased the overall efficiency of the evacuation and the early implementation of freeway lane reversals, also known as contraflow. A diagram of the plan, including the locations of the contraflow segments in shown in Figure 1. Although contraflow has been strongly advocated by many experts and non-experts alike, it has also been resisted by some highway agencies who feel that its benefits could be out-weighed by the safety problems and driver confusion that it could potentially create. One of the main problems in countering these views has been that contraflow has only been used a handful of times for evacuation and there are few, if any, quantitative studies of its characteristics on which to base its performance. Not only has this resulted in a lack of understanding of its utility, it has also greatly limited the ability to simulate contraflow evacuation processes with high degrees of confidence. When simulation studies of contraflow plans have been undertaken in the past, it was not clear what operational speeds or maximum flow rates would occur under emergency conditions. While some agencies assumed that traffic in contraflow lanes would flow the same as a normal lane, others assumed it could be as little as half of normal speed and flow $(\underline{2}, \underline{3})$.

Similar problems also exist for the analysis and modeling of evacuation traffic under conventional operation. There have been but a handful of studies that have collected and evaluated traffic flow characteristics during evacuations $(\underline{4}, \underline{5}, \underline{6}, \underline{7}, \underline{8})$. Such information becomes even scarcer when characteristics like maximum flow rates, operating speeds, headways, etc. are sought for different types of roadways. The study described in this paper was undertaken to address the need to improve the understand ing of flow characteristics during evacuations under both normat and contra-flow operation through an empirical examination of actual evacuation traffic.

The work presented here is based on traffic data collected on a variety of different roadway functional classifications and over a variety of urban and non-urbanized locations throughout the 


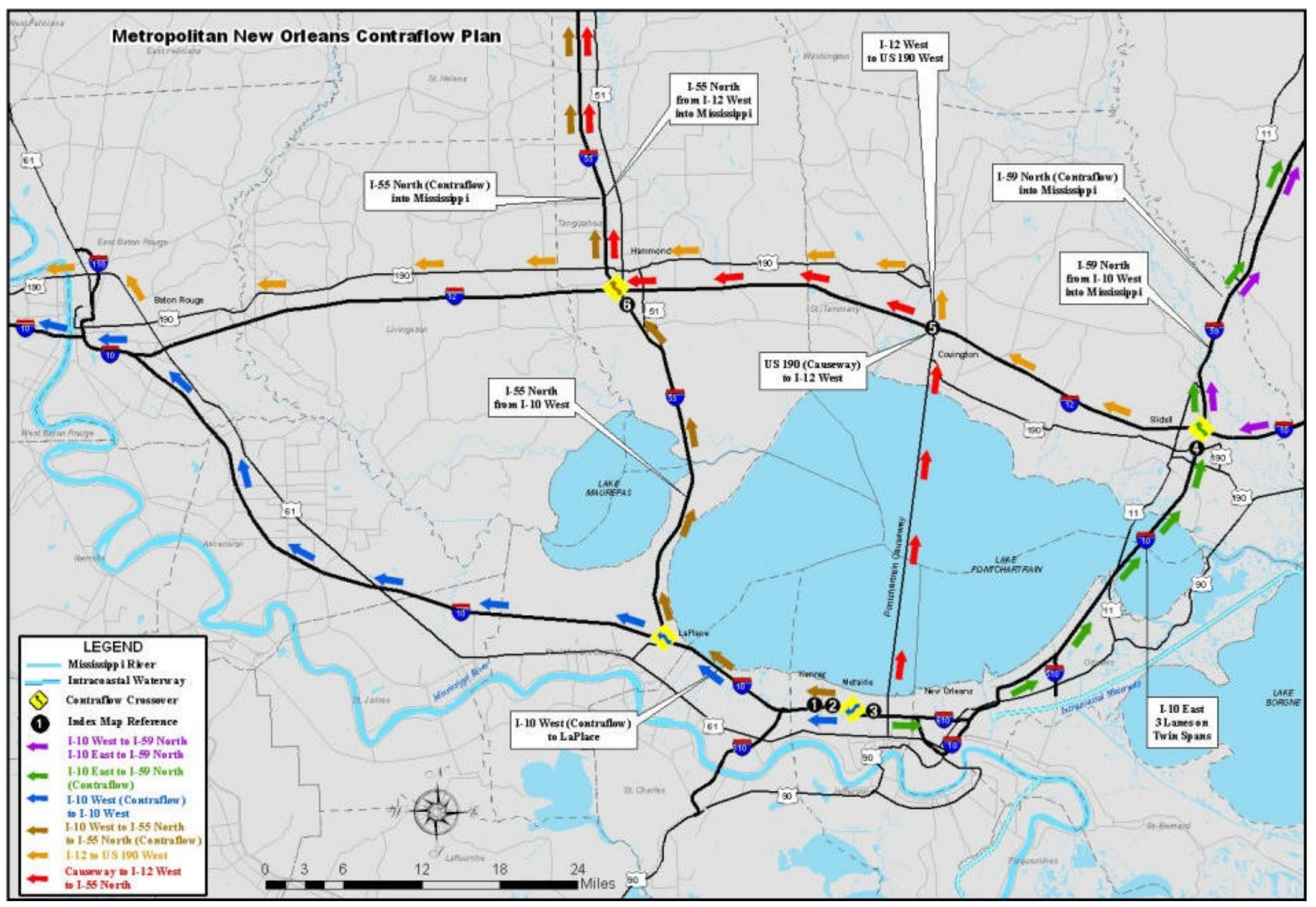

Figure 1. New Orleans Metropolitan Area Evacuation Map

(source: Louisiana Department of Transportation and Development) 
State of Louisiana during the Katrina evacuation Its primary objective is to characterize the general conditions of traffic flow under an evacuation condition and to more closely examine specific flow conditions to address lingering questions such as:

- How high do evacuations flows get?

- How long do high volumes last?

- How do volume characteristics differ between urban and rural areas?

- How do these characteristics compare based on different road classifications?

- How do maximum flows during an evacuation compare to Highway Capacity Manual (HCM) capacity estimates?

Another goal of this work was to study specific questions elated to the use of contraflow, including:

- How well did contraflow work during the evacuation?

- How did traffic flow in the contraflow lanes compare to traffic in the normal flow lanes?

Since this study is based on actual field data rather than estimates or simulation results, it is expected that the findings documented here will be valuable for future evacuation planning and simulation studies such as those used to estimate clearance time. Although the information contained in this paper reflects hurricane-specific evacuation conditions, it is also thought that they are likely applicable to other locations as well as other natural and intentional and unintentional man-made hazards.

\section{BACKROUND}

Data

The traffic volume data used as the basis of this paper was collected by the Louisiana Department of Transportation and Development (LA DOTD) Office of Planning and Programming as part of their statewide traffic data collection program. The objective of the program is to continuously record traffic volumes to monitor long-term traffic trends on a statewide level. The data are used primarily for aggregate-level planning and trend analyses. However, they can also be extracted more frequently and compiled for the assessment of traffic conditions associated with particular events; such as in this case, the evacuation for Hurricane Katrina.

In the program, traffic volumes are collected on a routine basis using a network of 82 permanent count stations located on various roads across the state. These automated recorders are arranged to provide a representative sample of traffic on all road classifications (freeway, arterial, collector, etc.) across the non-urbanized and urbanized regions of the state. During August 2005, 67 of the 82 LA DOTD data recorders were in operation. Of these, 16 of the stations were located on Interstate (I) Freeways, 22 were on US Highways, and the remaining 29 were on Louisiana State Highway (LA) system roads.

The analyses included in this study were based on traffic volume data acquired from the LA DOTD network during August 2005. The evacuation process took place over an approximate two day period from Saturday August $27^{\text {th }}$ through Sunday August $28^{\text {th }}$. Although the primary focus of the analyses are on flows that were recorded during the evacuation period, traffic data collected over the preceding three weeks was also used for comparative purposes to demonstrate typical trends during corresponding non-emergency periods. 


\section{The Evacuation Process}

Katrina made initial landfall on the southeast coast of Louisiana at approximately 6:00 AM on Monday, August 29, 2005. As would be expected, the earliest and most notable increases in traffic volume were recorded during the two days that preceded the storm's arrival and in areas closest to the storm's path. It has been suggested that the evacuation process also reflected the sequence (and urgency) of the preparedness messages that were conveyed by officials in Louisiana. The following timeline highlights many of the critical events and announcements related to the evacuation and storm development $(\underline{9})$ :

- Wednesday, August 24th

- Tropical Storm Katrina forms over the Bahamas in the Atlantic Ocean.

\section{- Thursday, August $25^{\text {th }}$}

- Two hours after Katrina reaches hurricane status, it makes landfall in southern Florida.

- The storm weakens while after passing over Florida, but regains hurricane status soon after entering the Gulf of Mexico.

\section{- Friday, August 26th}

- Governor Kathleen Blanco declares a State of Emergency in Louisiana.

\section{- Saturday, August 27th}

- 5:00am CDT - Katrina is upgraded to a Category 3 Hurricane.

- Governor Haley Barbour declares a State of Emergency in Mississippi.

- At the request of Kathleen Blanco, President George Bush declares a Federal State of Emergency in Louisiana.

- 4:00pm CDT - Louisiana and Mississippi implement contraflow evacuation operations plans on I-10, I-55, and I-59.

- 7:00pm CDT - As traffic volume increases steadily throughout the day, significant congestion is evident on I-10 at the Louisiana-Texas border, approximately 200 miles west of New Orleans.

- Throughout Saturday night and Sunday morning Louisiana Governor Blanco's staff works to contact local clergy to ask them to urge their parishioners to evacuate immediately. This was part of the Louisiana's pilot project "Operation Brother's Keeper" to help evacuate those who lacked transportation.

- Sunday, August 28th

- 2:00am CDT - Katrina is upgraded to a Category 4 Hurricane.

- 7:00am CDT - Katrina is upgraded to a Category 5 Hurricane.

- 9:30am CDT - Mayor Ray Nagin orders a first-ever "mandatory" evacuation for the City of New Orleans.

- 4:00pm CDT - The National Weather Service issues a Special Hurricane Warning to alert the public to the significant potential for overtopping of the levees by storm surge.

- 5:00pm CDT - Contraflow operations in Louisiana and Mississippi are terminated due to high winds and deteriorating weather conditions.

\section{- Monday, August 29th}

- 6:00am CDT - Katrina makes landfall near Buras Louisiana as Category 4 Hurricane.

The temporal progression of traffic during the evacuation relative to this timeline is illustrated graphically in Figure 2. In the figure, the combined hourly traffic flows from both of the outbound lanes of I-10 are shown from Thursday August $25^{\text {th }}$ through Monday August $29^{\text {th }}$. The 
LaPlace station is located about 30 miles west of New Orleans, immediately after the termination point of westbound contraflow. The average traffic flows on these corresponding days of the week from the preceding three weeks is also shown. The Monday morning landfall time of Hurricane Katrina is shown as the solid vertical line at the right of the figure.

Traffic Volume in Both Lanes (vph)

Storm Landfall

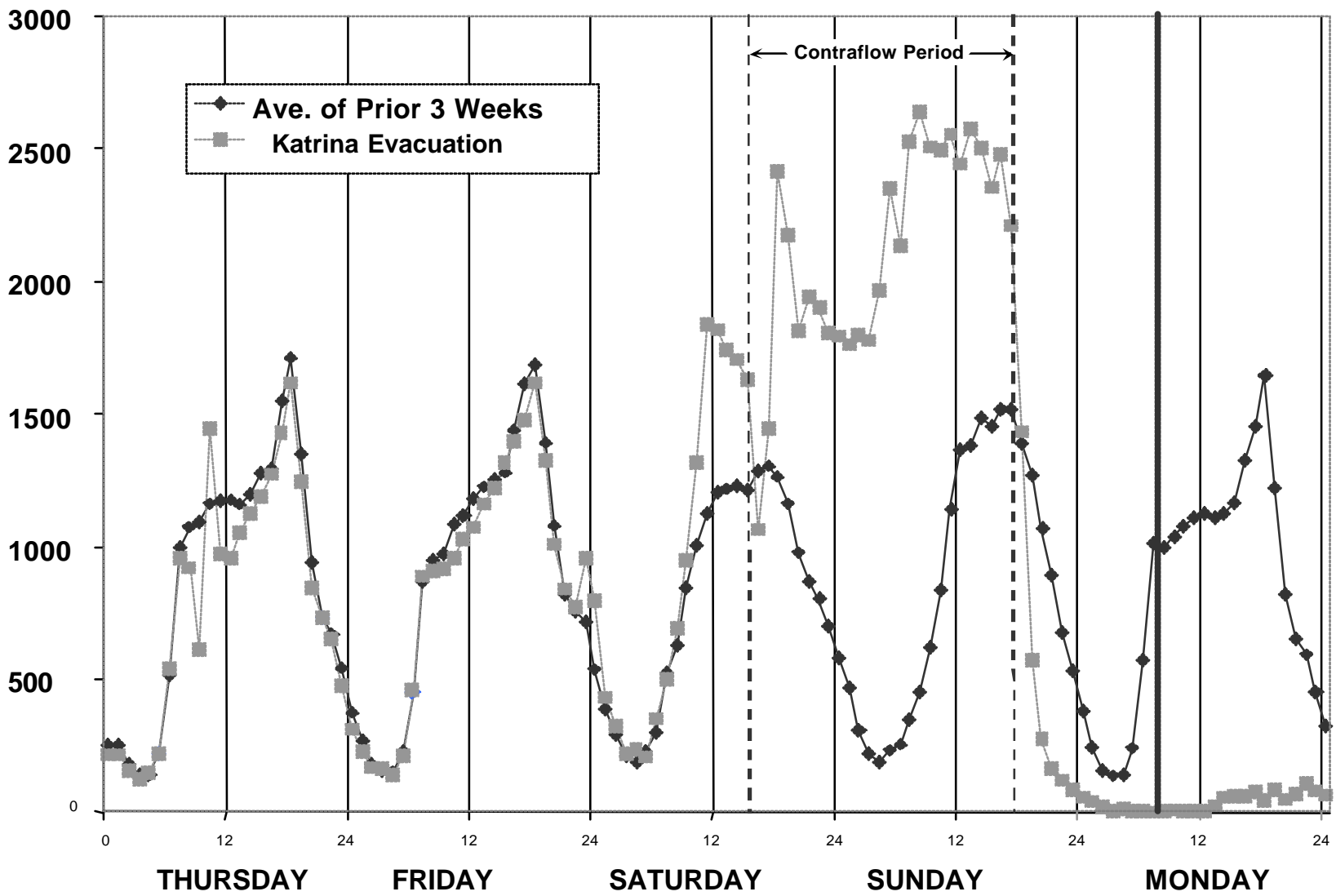

Figure 2. Westbound I-10 (outbound) Traffic Volume at LaPlace, LA

(Data source: LA DOTD)

The volume trend line of Figure 2 shows that despite the National Weather Service track forecasts and Governor's emergency declaration in Louisiana early on Friday, only marginally aboveaverage traffic movements occurred in the New Orleans areas on Friday night, August $26^{\text {th }}$. The slightly elevated at this location have also been suggested to be associated with a New Orleans Saints football game that was played that evening. Coinciding trends of inbound traffic suggests that some people were moving into threat areas; likely for the purpose of retrieving relatives and friends and to prepare and secure properties for the approaching storm. More obviously, Figure 2 shows that the major evacuation movement started the following morning, Saturday the $27^{\text {th }}$ and continued into the evening of the next day. This last-day departure pattern is not uncommon during hurricane evacuations. Prior experience in Louisiana and elsewhere has shown that evacuees typically do not begin moving until they feel directly and immediately threatened. 
Given the limitations and reliability of current weather forecasting, such certainty does not usually occur until 48 hours prior to landfall.

The trend line also shows some of the effects of contraflow operations on this segment of I- 10 . The contraflow implementation process required the placement of traffic control devices and the positioning of traffic enforcement police personnel at the inflow and outflow transition points. The volume trends in Figure 2 suggest that these activities restricted flow for a period of about two hours. The surge in volume after 4:00 PM shows the release of traffic demand stored behind the contraflow initiation point some 20 miles upstream of this count station. Following an oscillatory period, flow is shown to have remained relatively steady throughout the overnight hours of Saturday/Sunday. In the wake of Hurricane Katrina's upgrade to Category 5 status and the New Orleans Mayor's call for a mandatory evacuation of the city the next morning, traffic volume at the LaPlace station peaked late Sunday morning then held relatively steady near peak levels through the remainder of the afternoon. After 5:00 PM, however, traffic flow fell dramatically to under $100 \mathrm{vph}$ by 8:00 PM.

Another key finding from Figure 2 is an indication of the duration of the evacuation process. Depending on the criteria used to define the "evacuation period," Figure 2 shows that the evacuation lasted between 36 to 38 hours. This was well below estimates from studies conducted by the LA DOTD and US Army Corps of Engineers prior to the development of plans for contraflow. These agencies estimated that about 72 hours would be necessary to complete a full evacuation of the city. Thus, this data can also be used to counter claims by some that evacuation prior to storm was not possible because of traffic congestion. This graph shows that by about 10 hours prior to the storm landfall, traffic flow had dropped to a trickle; suggesting that everyone with the means and desire to evacuate had done so well before the worst of the storm conditions.

\section{MAXIMUM FLOW ASSESSMENT}

The characterization of traffic conditions during the Katrina evacuation focused mainly on the assessment of maximum flow volumes. Estimates of maximum sustainable flow under evacuation conditions are important because they are often used, for example, to forecast the required clearance time for locations based on combinations of population, response rate, and available roadway lane capacity. Maximum flows as a function of roadway type are also important when developing accurate simulation models of evacuation traffic. Maximum flows during the Katrina evacuation were categorized by the location or type area (urban or nonurbanized) as well as the roadway type (freeway, four-lane arterial, or two-lane arterial/collector).

Although sources such as the HCM include procedures for estimating maximum flow rates under routine conditions, they do not take into account special conditions that may diminish efficient traffic operations during an emergency. Prior reviews of the literature have also shown a lack of information to determine the capacity of highways operating in a reverse-flow operation (10). Combined, this lack of data has historically made it difficult to accurately assess regional evacuation strategies, set criteria for the implementation and termination of evacuation orders, and gauge the potential benefits of contraflow evacuation strategies. The following sections summarize the maximum evacuation flow rates on Louisiana roads during the Katrina evacuation. 


\section{Freeways}

As expected, the highest hourly flows during the Katrina evacuation were recorded on freeways. More unexpected was that the highest flow was recorded on sections of freeways entering and departing the Baton Rouge metropolitan area about 80 miles northwest on New Orleans. The elevated volume moving through this area is thought to be a reflection of the "funneling" effect created as evacuees moved toward the bridge crossings over the Mississippi River. This configuration was such that it provided a continuous saturation-level demand that was metered by the confluence of I-10 and I-12 some 10 miles upstream of the bridge. Lane specific flows downstream of the river crossing, noted as "I-10 Port Allen" in Table 1, peaked at nearly 2,000 vehicles per hour per lane (vphpl). It should be noted that the lane number designations in this (and all other tables) in this paper are numbered from left to right in the direction of travel. Thus, the left freeway lanes are shown as Lane 1 and the right lane as Lane 2. In locations where more than two lanes existed, the additional lanes were numbered similarly as Lane 3, Lane 4, and so on.

Despite the inflowing traffic at these locations it was surprising to see that nearly all of the freeway data stations in Table 1 showed maximum hourly flows below the ir HCM theoretical maximums. Most peaked in the range of 1,300 to 1,600 vphpl. While specifics such as the percentage of heavy vehicles were not known at the various locations, conditions were such that flows nearer to 1,700 to $1,900 \mathrm{vph}$ were expected. This expectation was based on the enormous demand generated by the evacuation as well as its duration. The lower than expected flow rates were also particularly unexpected in the New Orleans area where drivers would be expected to be more accustomed to driving under congested conditions (as reflected in the HCM driver population factor $-f_{p}$ ) and the likely presence of existing "ambient" or non-evacuation traffic demand (Error! Reference source not found.).

Table 1 includes a flow observation from New Orleans on I-10 approximately five miles from the central business district (CBD) and about one mile downstream of the I-10/I-610 confluence. The flow from this segment, shown as "I-10 W.B. New Orleans (Oaklawn)," suggests that it carried in excess of 6,000 vehicles in its four lanes between 11:00 AM and noon on Saturday, August $27^{\text {th }}$; with one of the lanes carrying a maximum flow of 2,555 vehicles during the hour. Unfortunately, however, the data shown for Lanes 3 and 4 is likely not valid since it was affected by the work zone traffic control configuration in this area. It is likely that temporary lane shifts resulted in double-counting of some vehicles that simultaneously overlapped the sensor zones in these lanes. The counts in Lanes 1 and 2 were not assumed to be affected.

For comparison purposes, Table 1 also segregates the maximum freeway flow observations based area type and includes corresponding "non-emergency" one-hour maximum flow volumes recorded at the same locations during the preceding three weeks of August 2005. It is interesting to note that the maximum evacuation flows on five of the nine urbanized-area freeway segments were actually less than those of the non-emergency periods. This was even true for the most populated cities of New Orleans and Baton Rouge. Revisiting the previous example of I- 10 in Baton Rouge, the evacuation flow peak of 2,939 vehicles per hour (vph) was about 14 percent less that the peak non-emergency flow of 3,437 vph. 


\begin{tabular}{|c|c|c|c|c|c|c|c|c|c|c|c|c|c|c|}
\hline \multirow[b]{2}{*}{ Location } & \multicolumn{7}{|c|}{ Evacuation Period } & \multicolumn{7}{|c|}{ Non-Emergency Peak (August) } \\
\hline & $\begin{array}{c}\text { Total } \\
\text { Vol. } \\
\text { (vph) }\end{array}$ & $\begin{array}{l}\text { Ln. } 1 \\
\text { Vol. } \\
\text { (vph) }\end{array}$ & $\begin{array}{l}\text { Ln. } 2 \\
\text { Vol. } \\
\text { (vph) }\end{array}$ & $\begin{array}{l}\text { Ln. } 3 \\
\text { Vol. } \\
\text { (vph) }\end{array}$ & $\begin{array}{c}\text { Ln. } 4 \\
\text { Vol. } \\
\text { (vph) }\end{array}$ & Time & Day & $\begin{array}{c}\text { Total } \\
\text { Volume } \\
\text { (vph) }\end{array}$ & $\begin{array}{l}\text { Total } \\
\text { Vol. } \\
\text { (vph) }\end{array}$ & $\begin{array}{l}\text { Ln. } 1 \\
\text { Vol. } \\
\text { (vph) }\end{array}$ & $\begin{array}{l}\text { Ln. } 2 \\
\text { Vol. } \\
\text { (vph) }\end{array}$ & $\begin{array}{l}\text { Ln. } 3 \\
\text { Vol. } \\
\text { (vph) }\end{array}$ & Time & Day \\
\hline Non-urbanized & & & & & & & & & & & & & & \\
\hline I-10 Chloe & 2,005 & 1,012 & 993 & ---- & ---- & 6:00 PM & Sun. & 1,293 & 662 & 631 & ---- & ---- & 3:00 PM & Sun. \\
\hline I-55 Fluker & 2,690 & 1,245 & 1,445 & ---- & ---- & 4:00 PM & Sun. & 1,188 & 803 & 385 & ---- & ---- & 4:00 PM & Fri. \\
\hline I-55 Fluker (c-flow) & 1,842 & 948 & 894 & ---- & ---- & 12:00 PM & Sun. & 834 & 513 & 321 & ---- & ---- & 5:00 PM & Sun. \\
\hline I-12 Livingston & 2,443 & 1,018 & 1,425 & ---- & ---- & 4:00 PM & Sat. & 1,991 & 927 & 1,064 & ---- & ---- & 5:00 PM & Sun. \\
\hline I-20 Monroe & 3,170 & 1,558 & 1,612 & ---- & ---- & 5:00 PM & Sun. & 2,338 & 1,288 & 1,050 & ---- & ---- & 5:00 PM & Fri. \\
\hline I-49 Carencro & 2,518 & 1,137 & 1,381 & ---- & ---- & 2:00 PM & Sun. & 2,342 & 1,037 & 1,305 & ---- & ---- & 6:00 PM & Fri. \\
\hline Urban & & & & & & & & & & & & & & \\
\hline I-10 B aton Rouge & 2,939 & 1,249 & 1,690 & ---- & ---- & 12:00 PM & Sat. & 3,437 & 1,336 & 2,101 & ---- & --- & 6:00 AM & Mon. \\
\hline I-10 Lake Charles & 2,772 & 1,335 & 1,437 & ---- & ---- & 3:00 PM & Sun. & 2,360 & 1,240 & 1,120 & ---- & ---- & 5:00 PM & Fri. \\
\hline I-10 Laplace & 2,637 & 1,160 & 1,477 & ---- & ---- & 8:00 AM & Sun. & 1,830 & 908 & 922 & ---- & ---- & 6:00 PM & Thur. \\
\hline I-10 Port Allen & 3,576 & 1,657 & 1,919 & ---- & ---- & 8:00 AM & Sun. & 2,766 & 1,312 & 1,454 & ---- & ---- & 5:00 PM & Fri. \\
\hline $\begin{array}{l}\text { I-10 W.B. New } \\
\text { Orleans (Oaklawn) }\end{array}$ & 6,017 & 687 & 1,275 & $2,555^{*}$ & $1,500^{*}$ & $\begin{array}{l}11: 00 \\
\text { AM }\end{array}$ & Sat. & 6,909 & 993 & 1,481 & $2,890^{*}$ & $1,545^{*}$ & 3:00 PM & Mon. \\
\hline I-10 Slidell & 1,900 & 1,007 & 893 & ---- & ---- & 2:00 PM & Sun. & 2,258 & 964 & 1,294 & ---- & ---- & 6:00 PM & Thur. \\
\hline I-20 Shreveport & 2,154 & 992 & 1,162 & ---- & ---- & 4:00 PM & Sun. & 2,034 & 988 & 1,046 & ---- & ---- & 8:00 AM & Mon. \\
\hline I-110 B aton Rouge & 812 & 327 & 243 & 242 & ---- & 2:00 PM & Sat. & 1,800 & 624 & 489 & 687 & ---- & 5:00 PM & Thur. \\
\hline I-210 Lake Charles & 1,309 & 735 & 574 & ---- & ---- & 5:00 PM & Sun. & 1,603 & 974 & 629 & ---- & ---- & 6:00 PM & Mon. \\
\hline
\end{tabular}

Note: Traffic data recorded in these lanes include vehicles from adjacent lanes due to temporary lateral lane shifting during construction activities

Table 1. Peak Flows on Louisiana Freeways

(Data source: LA DOTD) 
When comparing the peak flow rates in the urbanized and non- urbanized areas, the statistics also show that the maximum flows in rural areas were generally less than those of the urban areas, though not substantially so. One example where this was not the case was the segment of I-20 near Monroe, Louisiana (several hundred miles from the storm landfall location). In that location, I-20 carried more traffic than almost all of the urban freeways.

It is also notable that the evacuation versus non-emergency peak relationship in the nonurbanized areas was reversed from that of the urbanized areas. In all six cases, peak evacuation flows were substantially higher than those of the non-emergency peak periods. Again, the highest was recorded on I-20 near Monroe where a flow of 3,170 vph was recorded Sunday evening about 12 hours prior to storm arrival. This flow was nearly 36 percent higher than its August 2005 non-emergency peak flow.

\section{Contraflow Lanes}

Another significant knowledge gap has existed in the assessment and estimate of traffic flow rates under contraflow operation during evacuations. Although several studies have been published on reversible lane flow conditions, only one report (드) has suggested flow rates during an evacuation. However, this report was based on estimates, not direct field measurement. Fortunately, the LA DOTD data stations permitted traffic to be recorded in either direction. As a result, a station I-55 near Fluker, Louisiana about 15 miles south of the Mississippi state line and about 80 miles northwest of New Orleans, included about 24 hours of contraflow operation. The peak one-hour volume recorded during this period is illustrated in shaded line of Table 1.

The table shows that the highest hourly flow of contraflowing traffic occurred around mid-day Sunday when 1,842 vph moved through this segment. Interestingly, this flow was about 30 percent lower than the adjacent normal flow lanes of I-55 at the same location and the second lowest of any of the non-urbanized four-lane freeways. The only lower flow recorded during the evacuation was on I-210 south of Lake Charles near the Texas boarder. I-210 in this area is a bypass around the city and is typically less utilized than most of the other freeways in the sample.

The reason for the lower peak flow in the contraflow is not clear from information that was available. Some have suggested that flow contraflow lanes are adversely impacted by more cautious driver tendencies in reverse flowing lanes. However, officials from the Mississippi Department of Transportation (MDOT) have offered evidence quite to the contrary. MDOT officials have referenced reports from Mississippi Highway Patrol (MHP) officers who observed some drivers at the leading edge of the contraflow traffic stream traveling at speeds in excess of 90 miles per hour. Although they were not comfortable with this situation, MHP did not issue any violations as they wanted to keep traffic moving with as few interruptions as possible. To avoid similar situations in Florida, officials in that state plan to lead the contraflow traffic streams using DOT and police vehicles. Another theory for the lower than expected volume in the contraflow lanes was the strategy used for loading traffic into the section. The I-55 segment was loaded by channeling all northbound traffic from the normal-lanes of I-55 at an interchange about 25 miles to the south. Vehicles in these lanes were primarily composed of evacuees from the New Orleans metropolitan area via westbound I-10 in the city. 
The lane-specific flows in the contraflow segment also revealed several other notable characteristics relative to the other locations in the sample. For example, they were more evenly balanced (within 6 percent) between lanes than most of the other locations. It was among only four of the 13 two-lane freeway locations in which lane distribution differences of less than 10 percent were observed. The peak volume in the contraflow lanes during the evacuation was also significantly higher (120 percent) than the non-emergency peak flow of $831 \mathrm{vph}$ in these same lanes when they were flowing in a conventional operation.

Despite the lower than average peak flow in the contraflow lanes, the significant advantage of using contraflow was undeniable. These benefits are illustrated graphically in Figure 2. The right half of the graph shows the hourly northbound volumes during the Katrina evacuation. The area between the normal and contraflow curves represents the total additional traffic carried in the supplemental lanes. This total was 31,189 vehicles during the 24 hour period of contraflow. This graphic also contrasts the temporal characteristics of the Katrina evacuation with those of the Ivan evacuation one year prior, when contraflow was not used. As shown on the left side of the figure, the Ivan evacuation flow peaked at about 2,500 to 2,600 vph. Although this was similar to the peak Katrina flow in the normal lanes, it was well below the combined peak of $4,532 \mathrm{vph}$ on this segment of I-55 with contraflow. The total difference in northbound volume between the Ivan and Katrina evacuations on this section during the peak 48 hours of the evacuations was nearly 24,000 vehicles; or a 40 percent increase from 60,721 vehicles to 84,660 vehicles.

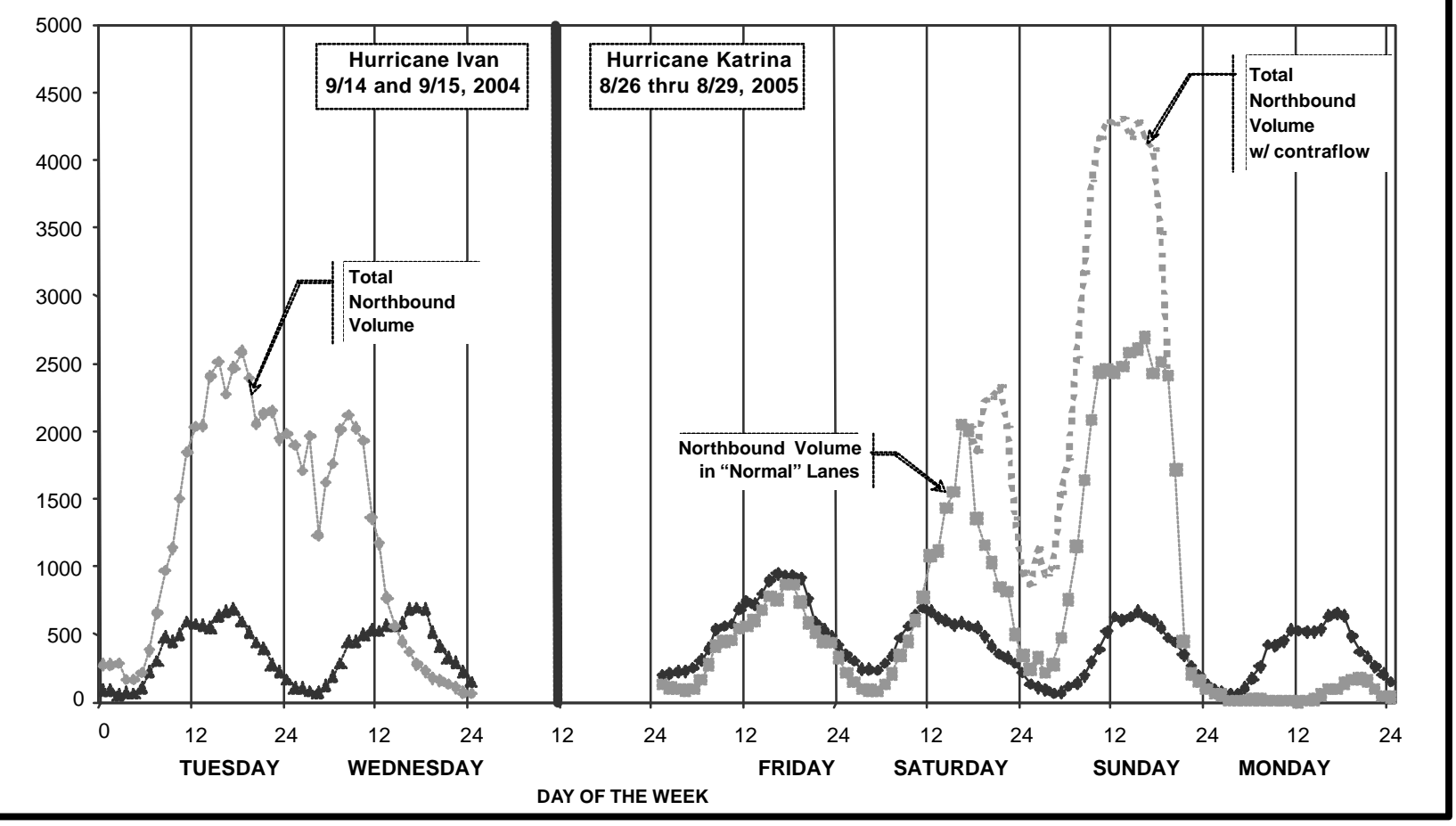

Figure 3. Northbound I-55 (outbound) Traffic Volume at Fluker, LA

(Data source: LA DOTD) 


\section{Four-Lane Arterial Roadways}

Another goal of the revised Louisiana evacuation plan was to better utilize non-freeway routes. This was for two reasons. The first was the obvious fact that a wider spread of demand over all routes would take better advantage of the available capacity of road network and thus decrease the total time required to evacuate the region. The second was that it was widely assumed that non-freeway routes have been historically underutilized in prior evacuations.

Peak hour flows for four-lane arterial highways included in LA DOTD data recording network are shown in Table 2. Like the freeway flow table, peak flows in Table 2 are grouped into the non-urbanized and urban area types and categorized based on evacuation and non-evacuation conditions. The highest flow rates on four-lane arterials during the evacuation were recorded on US Highway(US) 90 near Lafayette and US 190 just over the Mississippi River downstream of Baton Rouge. US 90 is a primary route for coastal areas south and west of New Orleans and US 190 provides one of the few crossing points over the Mississippi River in the region. Although neither of these routes are freeways, they both include segments of controlled access similar in character to freeways. Flow on both of these routes peaked at nearly $2,300 \mathrm{vph}$. The peak on US 90, nearer to the coast, occurred 20 hours earlier than the peak near Baton Rouge. Interestingly, however, the peak evacuation volume was very nearly the same as that of a typical commuter period.

The highest flow rates in a non- urbanized area were also recorded on US 90 near Centerville, Louisiana. This was not surprising given that this location was approximately 60 miles upstream of the station near Lafayette and was access controlled. US 90 at this location carried a peak flow of 2,313 vph, with the rightmost lane carrying a freeway- like flow of 1,327 vph. Similar to the freeway routes, the elevated evacuation flow here was also sustained above 1,500 vph for a period of about seven hours. A significant difference from the Lafayette location, however, was the variation from the $790 \mathrm{vph}$ non-emergency peak at this station.

Another point of note in Table 2 was that several of the locations experienced only moderate increases in volume over the non-emergency peak. Two data stations in the northern part of the state, near Monroe and Shreveport, even experienced decreases of 50 percent and 52 percent below non-emergency peaks, respectively.

Based on the roadway, traffic, and control conditions of these segments, the HCM suggests a lane capacity of 1,600 to 1,800 passenger cars per hour per lane (pcphpl) for an overall capacity in excess of 3,200 vph. It is noteworthy that, despite the demand generated by the evacuation as well as the near-ideal roadway and control conditions in several locations, none of the locations achieved these values. The lower than expected rates may have reflected the two-lane upstream section and traffic signal timing conditions along the route that moderated flow along the segment. Unfortunately, there were no records available to determine if signal timings were altered to facilitate evacuation flow. Although it should also be noted that there were also no near-capacity volumes at these locations during the preceding month.

\section{Two-Lane Arterial Roadways}

The final group of roads evaluated in the study were two-lane highways. The function of these routes in Louisiana were more diverse than the pervious group, ranging from primary and 


\begin{tabular}{|c|c|c|c|c|c|c|c|c|c|c|}
\hline & \multicolumn{5}{|c|}{ Evacuation Period } & \multicolumn{5}{|c|}{ Non-Emergency August Peak } \\
\hline \begin{tabular}{|l} 
Non-urbanized \\
US 90 Centerville \\
US 167 Lecompte \\
LA 15 Franklin \\
LA 1 Plaquemine \\
LA 143 Monroe
\end{tabular} & $\begin{array}{c}2,313 \\
346 \\
496 \\
1,740 \\
408\end{array}$ & $\begin{array}{l}986 \\
232 \\
323 \\
858 \\
147\end{array}$ & $\begin{array}{c}1,327 \\
114 \\
173 \\
882 \\
261\end{array}$ & $\begin{array}{l}\text { 6:00 PM } \\
\text { 5:00 PM } \\
\text { 6:00 PM } \\
\text { 1:00 PM } \\
\text { 5:00 PM }\end{array}$ & $\begin{array}{c}\text { Saturday } \\
\text { Sunday } \\
\text { Sunday } \\
\text { Sunday } \\
\text { Saturday }\end{array}$ & $\begin{array}{l}790 \\
299 \\
415 \\
632 \\
815\end{array}$ & $\begin{array}{l}502 \\
210 \\
289 \\
303 \\
198\end{array}$ & $\begin{array}{c}288 \\
89 \\
126 \\
329 \\
617\end{array}$ & $\begin{array}{l}\text { 6:00 PM } \\
\text { 8:00 AM } \\
\text { 5:00 PM } \\
\text { 8:00 AM } \\
\text { 6:00 PM }\end{array}$ & $\begin{array}{l}\text { Friday } \\
\text { Monday } \\
\text { Friday } \\
\text { Monday } \\
\text { Monday }\end{array}$ \\
\hline \begin{tabular}{l}
\multicolumn{1}{c}{ Urban } \\
US 61 Baton Rouge \\
US 61 LaPlace \\
US190 Denham \\
Springs \\
US 190 Miss. River \\
Bridge @ Baton Rouge \\
US 190 Port Allen \\
US 80 Shreveport \\
US 90 Lafayette
\end{tabular} & $\begin{array}{c}2,377 \\
1,937 \\
593 \\
2,251\end{array}$ & $\begin{array}{c}1,094 \\
560 \\
288 \\
1,019\end{array}$ & $\begin{array}{c}1,283 \\
1,377 \\
305 \\
1,232 \\
\end{array}$ & $\begin{array}{c}2: 00 \mathrm{PM} \\
12: 00 \mathrm{PM} \\
1: 00 \mathrm{PM} \\
6: 00 \mathrm{PM}\end{array}$ & $\begin{array}{l}\text { Sunday } \\
\text { Sunday } \\
\text { Saturday } \\
\text { Saturday }\end{array}$ & $\begin{array}{l}1,064 \\
1,463 \\
1,246 \\
2,208 \\
\end{array}$ & $\begin{array}{c}547 \\
456 \\
582 \\
1,060\end{array}$ & $\begin{array}{c}517 \\
1,007 \\
664 \\
1,148\end{array}$ & $\begin{array}{l}\text { 5:00 PM } \\
\text { 5:00 PM } \\
\text { 8:00 AM } \\
\text { 8:00 AM }\end{array}$ & $\begin{array}{l}\text { Monday } \\
\text { Thursday } \\
\text { Thursday } \\
\text { Thursday } \\
\text { Monday } \\
\text { Monday } \\
\text { Monday }\end{array}$ \\
\hline
\end{tabular}

Table 2. Peak Flows on Louisiana Four-Lane Arterial Roads

(Data source: LA DOTD) 
minor arterials to collector routes in more sparsely populated areas. Table 3 categorizes the twolane routes in the study in groups of US Highways, LA Primary Arterial Highways, and LA Secondary Arterial Highways.

The highest flow recorded during the evacuation period on any of these routes occurred on a segment of US 90 near Evangeline, Louisiana on Sunday afternoon when traffic flow peaked at $1,021 \mathrm{vph}$. The US 90 station is located about 50 miles west of Lafayette on an alignment parallel to and about one mile from I-10. Given this location, it is likely that much of the evacuation traffic was using US 90 as a continuation of US 90 from point further to the south and/or as an alternate travel route to I-10. Of the all routes in the US Highway category, US 90 had by the highest peak flow at nearly quadruple its highest non-emergency hourly flow.

Of the Louisiana Primary highway stations, LA 21 near Bogalusa recorded the highest evacuation flow at $915 \mathrm{vph}$. LA 21 is a north-south two-lane route that approximately parallels the Pearl River border between Louisiana and Mississippi. It is also located about midway between I-55 and I-59 effectively extending the Lake Pontchartrain Causeway bridge to the north. Daily evening non-emergency peak hourly flows at this location were typically about 350 to $400 \mathrm{vph}$. During the height of the evacuation, volumes were nearer to $900 \mathrm{vph}$, with a maximum flow of 915 vehicles per hour occurring between noon and 1:00pm on Sunday the $29^{\text {th }}$. It, like many of the other two-lane routes near New Orleans, experienced peak flow on Sunday afternoon about 18 to 20 hours prior to storm landfall. It is not clear if this occurred because other routes were congested or because evacuees in these areas had waited longer to depart.

It was also interesting that the peak flows on only one of the 15 count stations on the Louisiana secondary system experienced a peak flow above its non-emergency peak level. The lone station where this occurred was on LA 6, near Sabine, Louisiana where a modest, though statistically significant, 10 percent increase was observed. LA 6 also links to a crossing over the Sabine River which forms the border of Louisiana and Texas, so it may have been attractive for that reason. Although not included in the table, it was also noteworthy that a similar peak in traffic moving back in the opposite direction was clearly discernable on mid-day Monday after the storm had already moved inland.

Comparisons of two-lane volumes to their HCM estimated capacities was more difficult than the prior two categories because of the varying conditions. Under ideal conditions of design, traffic, and control, the HCM suggests a theoretical directional capacity of 1,700 passenger cars per hour (pcph) for two-lane roadways. The specific characteristics of LA 21 in this area would suggest a theoretical capacity closer to 1,100 to $1,300 \mathrm{vphpl}$. Thus, while not quite at its theoretical capacity, the utilization of this segment of roadway appeared to be much closer to its capacity. The inability of LA 21 to reach full utilization may, like LA 1, may also have been related to traffic signal controll at distant upstream and downstream locations along the route.

Another two-lane roadway location of note was on LA 10 in the 30 mile-wide non- urbanized belt between I-12 and the Mississippi border. While daily traffic peaks of 70 to $80 \mathrm{vph}$ were typical of this segment, flows peaked at 524 vehicles per hour during the afternoon of Sunday the $29^{\text {th }}$. This enormous increase in traffic was likely due to its use as an alternate route due to the closure 
of access from I-55 to westbound I-12 toward Baton Rouge. This phenomenon also highlights another of the intended effects of the LA DOTD evacuation plan.

\begin{tabular}{|c|c|c|c|c|c|c|}
\hline & \multicolumn{3}{|c|}{ Evacuation Period } & \multicolumn{3}{|c|}{ Non-Emergency August Peak } \\
\hline Location & $\begin{array}{c}\text { Total } \\
\text { Volume } \\
\text { (vph) }\end{array}$ & Time & Day & $\begin{array}{c}\text { Total } \\
\text { Volume } \\
\text { (vph) }\end{array}$ & Time & Day \\
\hline US Highway & & & & & & \\
\hline US 51 Fluker & 615 & 3:00 PM & Sunday & 155 & 5:00 PM & Friday \\
\hline US 84 Jena & 293 & 6:00 PM & Sunday & 140 & 6:00 PM & Friday \\
\hline US 165 Caldwell & 223 & 7:00 PM & Sunday & 220 & 5:00 PM & Friday \\
\hline US 165 Oakdale & 260 & 5:00 PM & Sunday & 343 & 3:00 PM & Thursday \\
\hline US 167 Winnfield & 209 & 4:00 PM & Sunday & 171 & 5:00 PM & Friday \\
\hline US 90 Evangeline & 1,021 & 3:00 PM & Sunday & 279 & 5:00 PM & Friday \\
\hline \multicolumn{7}{|c|}{$\begin{array}{c}\text { LA Primary Arterial } \\
\text { Highways }\end{array}$} \\
\hline LA 1 Caddo & 82 & 3:00 PM & Sunday & 107 & 10:00 PM & Friday \\
\hline LA 10 St. Helena & 524 & 4:00 PM & Sunday & 119 & 5:00 PM & Friday \\
\hline LA 21 Bogalusa & 915 & 1:00 PM & Sunday & 434 & 8:00 AM & Monday \\
\hline \multicolumn{7}{|c|}{$\begin{array}{c}\text { LA Secondary Arterial } \\
\text { Highways }\end{array}$} \\
\hline LA 2 Union & 141 & 1:00 PM & Sunday & 225 & 9:00 AM & Monday \\
\hline LA 4 Jackson & 120 & 3:00 PM & Saturday & 209 & 9:00 AM & Thursday \\
\hline LA 6 Sabine & 177 & 6:00 PM & Sunday & 160 & 1:00 PM & Sunday \\
\hline LA 8 Grant & 75 & 7:00 PM & Saturday & 145 & 9:00 AM & Monday \\
\hline LA 9 Bienville & 75 & 5:00 PM & Sunday & 117 & 9:00 AM & Friday \\
\hline LA 14 Abbeville & 33 & 12:00 PM & Sunday & 176 & 8:00 AM & Monday \\
\hline LA 17 Richland & 146 & 1:00 PM & Sunday & 232 & 8:00 AM & Friday \\
\hline LA 25 Franklinton & 329 & 2:00 PM & Sunday & 207 & 8:00 AM & Monday \\
\hline LA 28 Grant & 568 & 6:00 PM & Sunday & 793 & 8:00 AM & Monday \\
\hline LA 67 Clinton & 270 & 1:00 PM & Sunday & 327 & 6:00 PM & Thursday \\
\hline LA 121 Rapides & 102 & 1:00 PM & Sunday & 243 & 8:00 AM & Monday \\
\hline LA 126 Caldwell & 109 & 1:00 PM & Sunday & 157 & 8:00 AM & Monday \\
\hline LA 154 Bienville & 18 & 1:00 PM & Sunday & 36 & 1:00 PM & Thursday \\
\hline LA 175 Sabine & 59 & 3:00 PM & Sunday & 86 & 8:00 AM & Monday \\
\hline LA 463 Rapides & 31 & 1:00 PM & Sunday & 34 & 6:00 PM & Friday \\
\hline
\end{tabular}

Table 3. Peak Flows on Louisiana Two-Lane Roads

(Data source: LA DOTD) 


\section{CONCLUSION}

The results of this study are useful for illustrating several key facts about the flow conditions of traffic during the Katrina evacuation in specific and advance-notice mass evacuations in general. The first finding was that despite the demand generated by the evacuation (in excess of 500,000 outbound vehicles were recorded on the instrumented roads), traffic flows on Louisiana freeways during the Katrina evacuation did not consistently reach the theoretical capacity levels suggested by the HCM. Where HCM computations would have suggested capacities of 1,700 to 1,900 vph, maximum lane flows during the evacuation were primarily in the $1,000 \mathrm{vph}$ to $1,600 \mathrm{vph}$ range. In fact, no locations recorded flows in excess of 2,000 vph, although a station just outside of Baton Rouge recorded a lane flow of 1,919 vph. Another point of note was that traffic flow at only two of the six stations in the New Orleans and Baton Rouge metro areas exceeded typical commute period maximums.

Similar conditions were also evident on non-controlled access highways. Hourly lane flows on non-access controlled roadways never exceeded 1,000 vph. The highest flow on these road types peaked at between 800 and 1,000 vphpl. Considerably higher flows were, however, evident on multilane highways with freeway-type designs and controlled access. On these facilities, flows rivaled those of the actual freeways with maximum hourly volumes of 1,000 to 1,300 vphpl. All of these locations were, however, consistently below the HCM suggested maximums of 2,000 to 2,200 pcphpl under similar conditions.

Maximum flows on two-lane highways also showed similar trends. Flows in these locations were in the range of 900 to $1,000 \mathrm{vphpl}$. The highest flows were observed on two-lane highways downstream of multilane sections where inflow volume could be sustained at maximum levels. In areas where this type of "confined" demand did not exist, maximum flows of only 500 to 600 vph were observed.

The data included in this study also revealed quantitative characteristics of contraflow traffic flow for the first time. The maximum flows recorded under contraflow were in the 900 to 1,000 vphpl. These were 25 to 30 percent lower than most of the conventionally flowing lanes in Louisiana during the same period. It was interesting to note, however, that these rates were consistent with predicted estimates contraflow flow rates in prior evacuation planning studies which estimated sustained maximum hourly flow in contraflow lanes to be in the 1,000 vphpl range.

Despite its somewhat lower flow, the benefit of contraflow was also quite apparent. Data collected during the 24 hours of contraflow operation during the evacuation showed that the reversed section of I-55 carried an additional 31,000 vehicles out of threatened areas. Not only did this likely represent an additional 62,000 to 77,000 individual evacuees, the use of contraflow also indirectly helped by keeping the volume lower in the normal-flow lanes. This concept of "addition by subtraction" also helped to improve traffic flow on a regional basis as traffic was spread more widely throughout the branches of the road network.

Combined, these results suggest that practical maximum sustainable flows of:

- $\quad 1,300$ to $1,500 \mathrm{vphpl}$ on conventionally flowing (i.e., non-contraflow) freeways,

- 1,000 to $1,200 \mathrm{vphpl}$ on contraflowing freeways, 
- 800 to $1,000 \mathrm{vph}$ on four-lane non-controlled access arterial highways, and

- 500 to perhaps 1,000 vphpl on two-lane rural arterial highways would be reasonable for use in conducting evacuation planning and modeling studies. It should also be noted that the capacity diminishing effects of upstream bottlenecks for each data collection location were not considered as part of this study. The size of the sample area and the fact that the evacuation was a one-time event made it impossible to collect data at more locations. However, other researchers have recognized that there were likely many active bottlenecks within the network during the peak evacuation demand. Since the volumes observed at count stations downstream of an active bottleneck would have been controlled by the discharge capacity of the bottleneck and empirical research has established that discharge capacity is on the order of 10 percent lower than HCM theoretical segment capacity. Some of the lower-than-expected flow rates may not in fact be surprising if the metering capacity of the network bottlenecks was considered. For purposes of mass evacuation network modeling, the key question that should be answered in future research is whether the discharge capacity of normal flow and contraflow lanes under evacuation conditions is significantly different from discharge capacity under normal non-emergency flow.

This study also gives indications of other spatial and temporal aspects of the evacuation process. For example, traffic volumes recorded around the New Orleans area strongly suggest that that evacuation event took place over a period of about 36 to 38 hours. This provides contrary evidence to critics who initially claimed that many of the people who remained in the city after the devastation brought by breaches in the levee system did so because they were unable to evacuate the city because of traffic congestion. It further suggests that all residents with the ability and desire to evacuate the city likely did so well before the onset of the fiercest of the storm conditions.

From a spatial perspective, differences between the operation of the various roadway classifications in the urbanized and non-urbanized areas were also evident. When combined with the temporal data, the volume counts on urbanized-areas freeways suggested that the evacuation process in the most populated cities of New Orleans and Baton Rouge did not appear significantly different from non-emergency periods in these areas as maximum flows were nearly the same, if not slightly lower, than normal commuter peaks. The major difference, obviously, was that the peak period during the evacuation lasted nearly two days rather than two hours.

Data recorded in rural areas showed another of the obvious, though often overlooked aspects of hurricane evacuations. This is that mass evacuations are primarily rural events that impact the road system and its support resources well outside of populated areas to degrees that are often not accounted for in emergency planning. Rural freeway volumes were shown to be two to three times their normal level. Several location were as much as 10-times higher than normal. With this level of additional traffic comes the need for additional support services such as fuel, repair, medical, rescue, and personal hygiene necessities in areas which are not necessarily equipped to accommodate them. When vehicles run out of fuel or require service in some of these areas, assistance may be several hours away. Conditions such as these compound the difficulties of an evacuation and were illustrated during the Rita evacuation when drivers were stranded because they were unable to refuel their vehicles.

\section{ACKNOWLEDGEMENTS}


The author gratefully acknowledges the technical assistance provided by Mr. Ben McArdle of the Department of Civil and Environmental Engineering at Louisiana State University for his work in converting and collating the flow statistics from the data files. The author also thanks the officials and staff of the LA DOTD, including Dr. Eric Kalivoda, Stephen Glascock, and Joan Black for providing all of the traffic data files used in this project as well as the anonymous technical experts who reviewed and comment on this paper.

\section{REFERENCES}

1. Southeast Louisiana Hurricane Evacuation Study: Transportation Model Support Document, Post, Buckley, Schuh \& Jernigan, Inc. Tallahassee, FL, 2001.

2. Interstate Highway 37 Reverse Flow Analysis, Texas Department of Transportation Technical Memorandum, Corpus Christi, TX, 2000.

3. Evacuation and Clearance Times. Florida Department of Community Affairs, Florida Division of Emergency Management. www.dca.state.fl.us/fdem/bpr/Response/Plans/nathaz /hurricanes/clearance_time_expl.htm. Accessed February 25, 2003.

4. Hurricane Floyd Assessment - Review of Hurricane Evacuation Studies Utilization and Information Dissemination, Post, Buckley, Schuh \& Jernigan, Inc. Tallahas see, FL, 2000.

5. Reverse Lane Standards and ITS Strategies Southeast United States Hurricane Study Technical Memorandum 3, Post, Buckley, Schuh \& Jernigan, Inc. Tallahassee, FL, 2000.

6. Wolshon B., A. Catarella-Michel, and L.L. Lambert. Louisiana Highway Evacuation Plan for Hurricane Katrina: Proactive Management of Regional Evacuations. ASCE Journal of Transportation Engineering, Vol. 132, No. 1, 2006, pp. 1-10.

7. Lim, Y.Y. and B. Wolshon, "Modeling and Performance Assessment of Contraflow Evacuation Termination Points," Transportation Research Record 1922, 2005, pp. 118-127

8. Williams, B.M., A.P. Tagliaferri, S.S. Meinhold, J.E. Hummer, N.M. Rouphail. Simulation and Analysis of Freeway Lane Reversal for Coastal Hurricane Evacuation. ASCE Journal of Urban Planning and Development, Vol. 133, No. 1, 2007, pp. 61-72.

9. The Federal Response to Hurricane Katrina: Lessons Learned, The White House, Washington, DC, 2006. www.whitehouse.gov/reports/katrina-lessons-learned/chapter3.html Accessed December 15, 2003.

10. Wolshon, B and L.L. Lambert. Convertible Lanes and Roadways, National Cooperative Highway Research Program - Synthesis 340, Washington DC, 2004, 92 pp. 